\title{
Training Needs Assessment of Reproductive Health and Family Planning Leaders of Leadership Development Programs in Pakistan
}

\author{
Sayeeda Amber Sayed ${ }^{1, *}$, Agha Ajmal ${ }^{2}$ \\ ${ }^{1}$ Department of Family Medicine, University of Calgary, Alberta, Canada \\ ${ }^{2}$ Department of Health Services Policy and Management, University of South Carolina, Columbia, USA
}

Email address:

sayeedaamber@hotmail.com (S. A. Sayed), ajmal.agha@gmail.com (A. Ajmal)

\section{To cite this article:}

Sayeeda Amber Sayed, Agha Ajmal. Training Needs Assessment of Reproductive Health and Family Planning Leaders of Leadership Development Programs in Pakistan. Science Journal of Public Health. Vol. 3, No. 4, 2015, pp. 538-543. doi: 10.11648/j.sjph.20150304.22

\begin{abstract}
The issue of workforce training and competency is central to the success of any public health system. The first step in designing training is to conduct a need assessment for an effective training program. In this research, we have accessed the training needs of the leaders of Leadership Development Program for mobilizing reproductive health; the vision of program was to develop a critical mass of diverse leaders, who can work individually and collectively and their efforts can improve reproductive health options and overall quality of life, especially for vulnerable populations in Pakistan. A cross-sectional study design was used to collect data by means of self-administered questionnaires from Reproductive Health and family planning leaders of the Leadership Development program from all over Pakistan. A total of 40 reproductive and family planning leaders participated after informed consent through non-probability convenience sampling. It was found that responding to felt needs is important for improving performance in health care system. Uses of practical, problem based learning methods are generally not included in the trainings. The priority areas in the current health scenario of Pakistan as identified by the study participants include training in disaster management, budget management, emergency preparedness and monitoring and evaluation. Need of communication skills training for health education was also highlighted for better reproductive health of the Pakistani population. The study indicated that training needs of Reproductive health and family planning leaders were heterogeneous and differed within professions by the tasks performed. Therefore, it is important to assess the tasks performed and training needs in leadership program participants in order to allocate training resources appropriately. There should be a permanent system for reviewing training needs.
\end{abstract}

Keywords: Leadership Development, Training Need Assessment, Reproductive Health and Family Planning leaders, Pakistan

\section{Introduction}

It is well recognized that assessing the needs and the level of skills and knowledge of potential participants before implementing the training considerably enhances the outputs of informal and formal training activities. Assessing the training needs of local public health workers is an important step toward providing appropriate training programs in emergency preparedness and core public health competencies The Training Need Assessment provides a useful tool for the management of the changes required for health sector reforms in many countries. [1] The immediate gains are motivated participants and a higher satisfaction of their immediate needs. The long-term gains are longer-lasting effects of training, when needs have been addressed at the right time in the right

way. [2]

\subsection{Importance of Training in Public Health}

Educating Public Health Professionals in the 21st Century reinforced the call to train the public health workforce specifically those who work in public health departments or agencies in core public health skills. Over the last decade, several committees, agencies, and reports have identified public health worker training as a critical component of a well functioning public health system.

It has been well established that most public health agency employees need training in core public health competency 
areas. In fact, many public health agency workers enter the public health workforce with training in only their specific technical area e.g., health education, environmental health, or nursing. While technical expertise is critical, basic awareness and understanding of core public health competencies is also imperative for a public health agency to function well. [3]

Through a national process that included input from public health practitioners, the Council on Linkages between Academia and Public Health Practice developed a list of core public health competencies, which are organized within the 10 essential public health services. The Council recommends that all public health workers have at least a basic awareness of these competencies, and depending on the competency area, that workers in specific jobs should attain defined skill levels and/or proficiencies. 4

\subsection{The 10 Essential Public Health Services}

1. Monitor health status to identify community health problems.

2. Diagnose and investigate health problems and health hazards in the community.

3. Inform, educate, and empower people about health issues.

4. Mobilize community partnerships to identify and solve health problems.

5. Develop policies and plans that support individual and community health efforts.

6. Enforce laws and regulations that protect health and ensure safety.

7. Link people to needed personal health services and assure the provision of health care when otherwise unavailable.

8. Assure a competent public health and personal health care workforce.

9. Evaluate effectiveness, accessibility, and quality of personal and population-based health services.

10. Research for new insights and innovative solutions to health problems. [4]

\subsection{Importance of Assessing the Public Health Workforce}

The need to assess the public health workforce, emphasizing that the training, education, and competency of public health workers are critical components of public health infrastructure: The issue of workforce training and competency is central to the success of any public health system. In addition, an assessment of current competency levels and needs is essential to develop and deliver the appropriate competency-based training, as well as to evaluate the impact of that training in practice settings. [5]

Public health researchers have explored two methods of surveying the public health workforce to identify competency-training needs. The first surveys all public health workers in all competencies. This method follows the rationale that all workers should have at least a basic awareness of all core competencies. The second method identifies competencies that are important to specific job classifications, asks the worker to self-identify a job classification, and then survey the worker in the competencies important to that classification. [6] This method reduces the time burden on the worker to complete the assessment.

\subsection{Leadership Development in Health Care in Pakistan}

$21^{\text {st }}$ century is envisaged as a time of change in the health care system. The traditional roles of the public health professions are changing as direct patient care is de-emphasized and assessment and quality assurance roles are highlighted. [7] This shift in roles is broadening the spectrum of organizations which provide community/public health services so that many private and non-profit providers, such as health maintenance organizations and managed care plans, are assuming responsibilities that were once entirely within the domain of governmental public health agencies.

\subsection{The Leadership Development Program for Mobilizing Reproductive Health (LDM)}

The LDM program, implemented by the Institute of International Education (IIE) and funded by the David and Lucile Packard Foundation, has offered leadership development opportunities to selected individuals since 2000.8 The focus of program was to build strong leadership to impact the health and lives of women and families. The vision of program was to develop a critical mass of diverse leaders; working individually and collectively, has affected systemic changes that improve reproductive health options and overall quality of life, especially for vulnerable populations. [9]

The LDM program believed that the leadership is an ongoing process, which requires continuing development of leaders. The underlying program theory is that the continuing trainings of fellows would expand their abilities to lead effectively and will work collectively to enhance reproductive health (RH) programs.

The LDM program was initiated in Pakistan (called LDM-Pakistan hereafter) in 2001. By 2010, the program had vibrant network of 173 fellows from all over the country, with chapters in provinces Sindh and Punjab and Federal capital, Islamabad, Pakistan. LDM-Pakistan Fellows belonged to diverse sectors including service delivery, the media, researchers, policy makers and advocates. 10 They were heads of organizations, community change agents and health practitioners. While, before 2006, the program supported fellows to acquire trainings from out of country and within the region, in 2006 and after, more and more training opportunities in local setting were explored and utilized. This research contributes to an understanding of those individuals' perceived training needs who are currently leading the RH/FP sector in Pakistan.

\subsection{Objectives}

To determine the Training Needs Assessment of Reproductive Health and Family Planning Leaders of Leadership Development Programs in Pakistan 


\section{Methods}

Study design: Cross-Sectional Study Design

Setting: Reproductive Health and family planning leaders of the Leadership Development program from all over Pakistan

Duration of study: September 2010 to November 2010

Sample size: 40 Reproductive Health and Family Planning Leaders

Sampling technique: Non Probability convenient sampling Sample selection:

Inclusion criteria: All the Public Health workers involved in Reproductive Health and Family Planning Services and are LDM fellows

Exclusion criteria: The LDM fellows that do not give consent to be part of the study

Data collection procedure: Data is collected by means of self-administered questionnaires. A specially-designed questionnaire covered demographic characteristics, current training needs, barriers and facilitating factors in receiving training, importance of 51 different training topics covering eight broad themes: fundamentals of research, topics in epidemiology and biostatistics, specific topics related to Reproductive Health and family planning, ethics, financing, leadership, and planning, program implementation, monitoring and evaluation. Review of records, databases and documents regarding the Leadership Development programs and previous work on Reproductive Health and family planning workers' need analysis was studied to develop the questionnaire.

Data analysis procedure: The statistical analysis was performed using Statistical Package for Social Sciences (SPSS) version 11.5 for windows. Descriptive methods were used to summarize the data. Frequencies were calculated for categorical and mean and standard deviations for continuous variables.

Ethical Considerations: The informed consent was sought from all participants. Participants were given the option to leave study anytime or not answer any of the study questions. Data was coded for confidentiality. The results of the study were shared with the study participants soon after the study.

\section{Results and Discussion}

The data analysis revealed that majority of the leaders was in the age bracket of $31-50$ years $(85 \%)$. This makes sense as the leadership development program in RH/FP sector mainly influenced the mid level leadership. 57.5\% of the females were working in the Reproductive health sector; however presence of $47.5 \%$ male leaders showed that male also realized the importance of working in the RH and FP areas. Karachi and Islamabad being the hub of leadership activities; had the maximum number of fellows ranging from $42.5 \%$ to $30 \%$. Majority $(65 \%)$ of the fellows of leadership development program had 16 years of education, which showed that the leaders had sound educational background. $75 \%$ of the study participants had degrees in Social sciences while $22.5 \%$ had degrees in Public health and there was a small percentage of individuals who had the literature background.

Table 1. Socio-demographic information of participants.

\begin{tabular}{|c|c|c|c|}
\hline Socio-demographics & & $\mathrm{n}=\mathbf{4 0}$ & $\%$ \\
\hline \multirow{4}{*}{ Age of the Leaders } & 20 to 30 years & 2 & 5 \\
\hline & 31 to 40 years & 17 & 42.5 \\
\hline & 41 to 50 years & 17 & 42.5 \\
\hline & 51 to 60 years & 4 & 10 \\
\hline \multirow{2}{*}{ Gender } & Male & 17 & 42.5 \\
\hline & Female & 23 & 57.5 \\
\hline \multirow{5}{*}{ Location in Pakistan } & Karachi & 17 & 42.5 \\
\hline & Lahore & 5 & 12.5 \\
\hline & Islamabad & 12 & 30 \\
\hline & Baluchistan & 4 & 10 \\
\hline & KPK & 2 & 5 \\
\hline \multirow{4}{*}{$\begin{array}{l}\text { Years of education } \\
\text { completed }\end{array}$} & 16 years & 26 & 65 \\
\hline & 18 years & 6 & 15 \\
\hline & 20 years & 4 & 10 \\
\hline & More than 20 years & 4 & 10 \\
\hline \multirow{3}{*}{$\begin{array}{l}\text { Area of } \\
\text { Specialization/Degree }\end{array}$} & Public health & 9 & 22.5 \\
\hline & Social Sciences & 30 & 75 \\
\hline & Literature & 1 & 2.5 \\
\hline \multirow{4}{*}{$\begin{array}{l}\text { Length of time working in } \\
\text { public health }\end{array}$} & Less than 2 years & 1 & 2.5 \\
\hline & 2 to 5 years & 6 & 15 \\
\hline & 6 to 10 years & 15 & 37.5 \\
\hline & More than 10 years & 18 & 45 \\
\hline \multirow{4}{*}{$\begin{array}{l}\text { Length of time working for } \\
\text { Reproductive Health and } \\
\text { Family Planning in Pakistan }\end{array}$} & Less than 2 years & 1 & 2.5 \\
\hline & 2 to 5 years & 5 & 12.5 \\
\hline & 6 to 10 years & 15 & 37.5 \\
\hline & More than 10 years & 19 & 47.5 \\
\hline \multirow{3}{*}{$\begin{array}{l}\text { Type of organization } \\
\text { employed }\end{array}$} & Private Organization & 23 & 57.5 \\
\hline & $\begin{array}{l}\text { Public Private } \\
\text { Organization }\end{array}$ & 7 & 17.5 \\
\hline & Public Organization & 10 & 25 \\
\hline \multirow{5}{*}{$\begin{array}{l}\text { Length of time in the current } \\
\text { job }\end{array}$} & Less than 1 year & 9 & 22.5 \\
\hline & 1 to 2 years & 10 & 25 \\
\hline & 5 years & 7 & 17.5 \\
\hline & 6 to 10 years & 5 & 12.5 \\
\hline & More than 10 years & 9 & 22.5 \\
\hline \multirow{2}{*}{$\begin{array}{l}\text { Formal \& Written Job } \\
\text { descriptions for current job }\end{array}$} & Yes & 34 & 85 \\
\hline & No & 6 & 15 \\
\hline
\end{tabular}

It was noteworthy that $45 \%$ of the study participants were working in this field for more than 10 years. $47.5 \%$ of the study participants were working in the reproductive health and family planning services for more than 10 years. $60 \%$ of the leaders were in private organizations while only $25 \%$ of the workers belonged to public service organizations. A mixed trend was noted regarding the job continuity, $22.5 \%$ of the Reproductive health and family planning leaders of the leadership development program have switched their jobs within a year. However the same number of leaders continued to serve in an organization for more than 10 years. It was commendable to note that $85 \%$ of the Reproductive health and 
family planning leaders had written job descriptions, which helped them to identify their job responsibilities.

Table 2. Main tasks in relation to the job.

\begin{tabular}{lll}
\hline Description & $\mathbf{n}$ & $\mathbf{\%}$ \\
\hline Management & 19 & 47.5 \\
Administration & 5 & 12.5 \\
Supervision & 3 & 7.5 \\
Resource Mobilization & 3 & 7.5 \\
Fund Raising & 2 & 5 \\
Curriculum Development & 1 & 2.5 \\
\hline
\end{tabular}

Table 2 show that majority of the fellows of leadership development program were serving in the leadership roles and more than $60 \%$ are in the top ladder where they were managing and supervising others.

Table 3. Priority five Skill Areas which are needed in the job.

\begin{tabular}{lll}
\hline Description & n & \% \\
\hline Financial /Accounting Skills & 21 & 52.5 \\
Report Writing Skills & 11 & 27.5 \\
Negotiation Skills & 2 & 5 \\
Program Management Skills & 4 & 10 \\
Communication Skills & 2 & 5 \\
\hline
\end{tabular}

Table 3 illustrates the priority skills areas which the leaders mentioned necessary for their job performance. $53 \%$ of the leaders highlighted the importance of financial management for their effective working.

Table 4. No of Trainings attended in the last one year

\begin{tabular}{lll}
\hline Description & $\mathbf{n}$ & $\%$ \\
\hline No training & 11 & 27.5 \\
1 training & 17 & 42.5 \\
2 trainings & 6 & 15 \\
3 to 5 trainings & 4 & 10 \\
More than 5 trainings & 2 & 5 \\
\hline
\end{tabular}

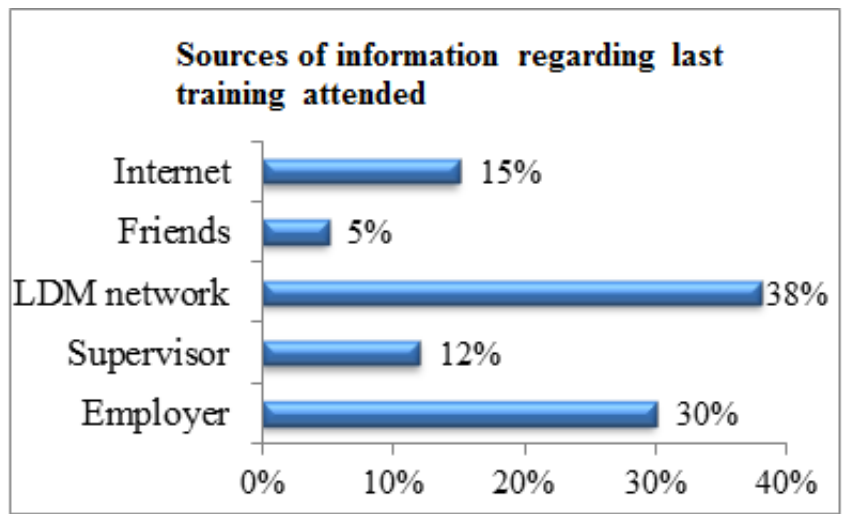

Graph 1. Bar graph showing source of information for the last training attended by the leaders.
$42 \%$ of the reproductive and family planning leaders availed one training opportunity during the last year. $38 \%$ received information regarding the training opportunity through their networking which they had developed being a fellow of the Leadership Development Program. 30\% individuals attended training, which was recommended by the employers.

Priority training needs identified by RH/FP leaders:

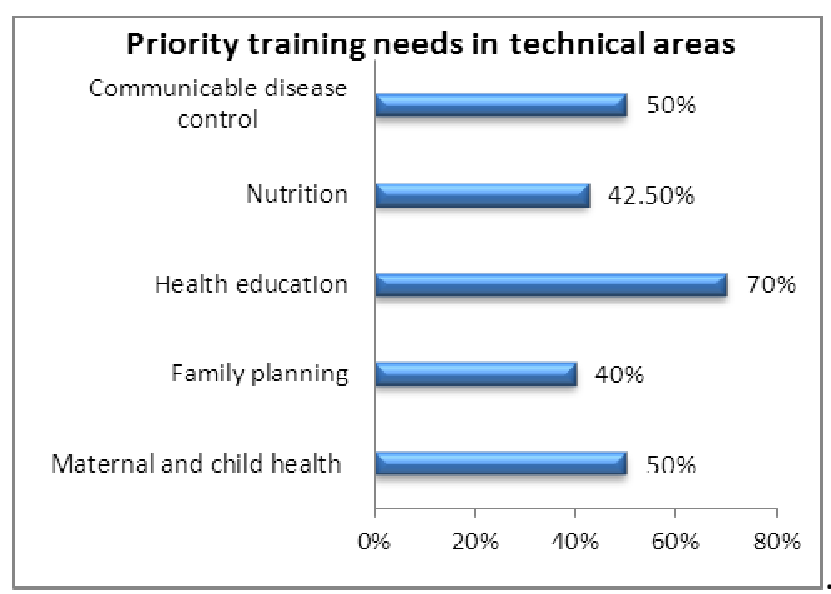

Graph 2. Additional training needs in the technical areas.

It is noteworthy that $70 \%$ of the individuals identify training need in the area of Health Education followed by maternal and child health and communicable disease control knowledge

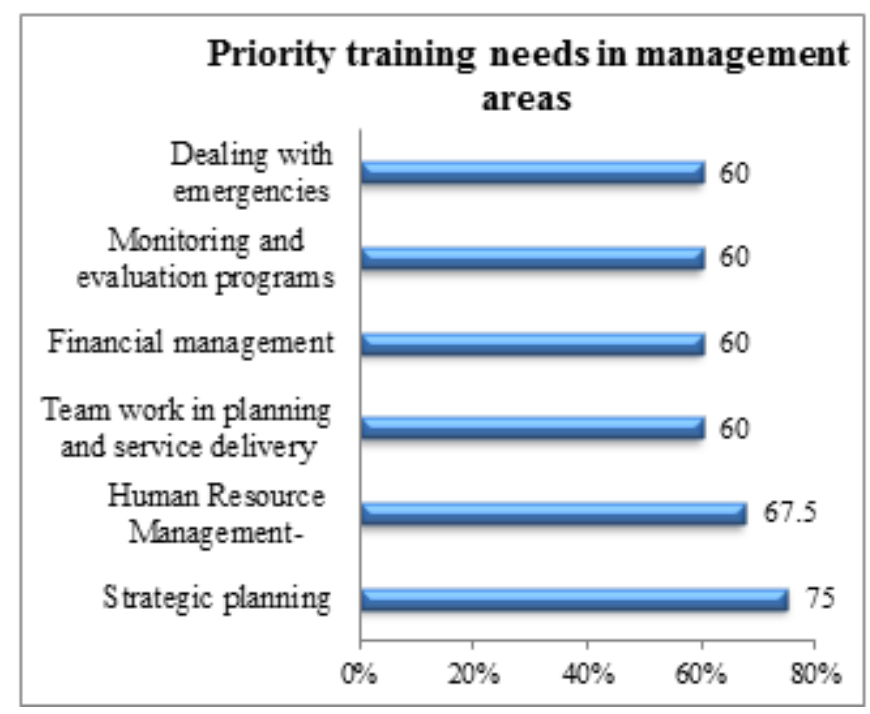

Graph 3. Additional training needs in the management areas.

$75 \%$ of the Leadership development program fellows mention the need of training in strategic planning while $67.5 \%$ need training in Human resource management. $60 \%$ Participants mention the need of training in team work, financial management, monitoring and evaluation of program and dealing with emergencies. 


\section{Priority Areas for Personal Development}

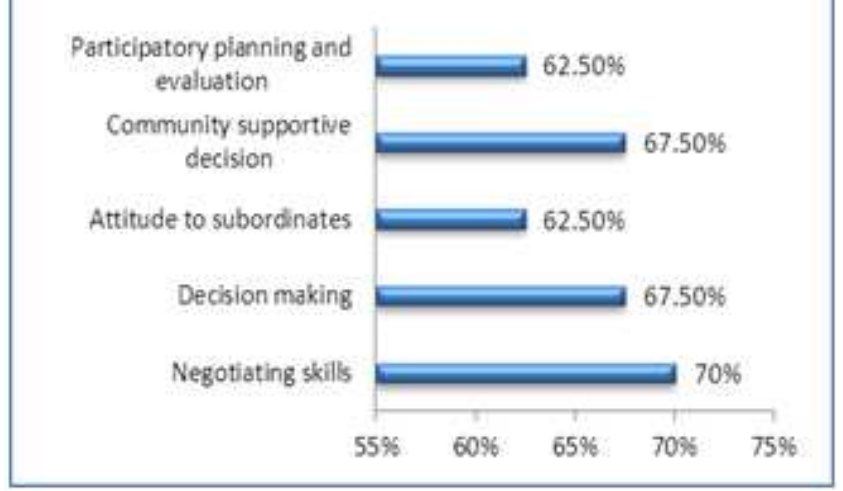

Graph 4. Additional training needs for Personal Development.

$70 \%$ of the respondent pointed out training needs in the negotiating skills and $67.5 \%$ participants need training in decision making skills and community supportive decisions.

$80 \%$ of the respondents also mentioned the need of training in disaster management while $77 \%$ showed interest in the trainings of budget management and monitoring. $72.5 \%$ also pointed out the need of trainings in emergency preparedness and strategies for health and risk communication.

In Pakistan with situation of low motivation of health personnel, responding to felt needs is important for improving performance. The value of training in communication skills and use of practical, problem based learning methods are generally not included in the trainings $[11,12]$

The Training Need Assessment helped in the identification of the areas where the current training was failing to address the problems; and where the felt needs of the RH/FP leaders coincided with the organizational needs. This produced a long list of areas in which current training was deficient, particularly in the development of practical management skills. Selecting those areas seen as felt needs and included in the latest job descriptions, such as supervision and interpersonal skills training, could then be prioritized. [13]

Priority areas of trainings in the current scenario of Pakistan include training in disaster management, budget management and monitoring, emergency preparedness and strategies for health and risk communication for better reproductive health of the Pakistani population.

The study signifies that Training needs were heterogeneous and differed within professions by the tasks performed. Therefore, it is important to assess the tasks performed and training needs in leadership program participants in order to allocate training resources appropriately.[14]

A review of studies of health professionals in the United States and Europe concluded that the validity of self-assessment of performance was low to moderate, but could be improved with appropriate training [15]. Our results suggested that self-assessment of overall knowledge of Training needs can be used as a measure to design effective trainings in a resource-limited setting. [16]

The Training Need Assessment method sets up a channel of communication with the health staff and clarify set of priorities that can be discussed and reviewed. [17] With the decentralization of health sector, development of teamwork and accountability at levels is crucial for improved health outcomes and health care system in Pakistan. This cut across the vertical lines of responsibility with in the technical programs and affects all supervisors in a province. The study participants highlighted the training need for collaborative team efforts. [18]

With the devolution process, more focused attention on governance at the district level, the health policymakers failed to strengthen this system. Today, Pakistan is at a critical stage of political change, with constitutional amendments again restructuring government systems. If the impact of recent devolutionary changes is not deeply understood, then the capacity to respond appropriately will be limited.19 In the present climate of international health sector reform, there are often rapidly changing rhetoric plans but slow implementation of reforms due to poor communication and structural weaknesses in local systems. [20]

\section{Conclusion}

The purpose of a training needs assessment in health care is to identify performance requirements in order to help direct resources to the areas of greatest need, fulfilling the goals and objectives, improving productivity and providing quality products and services. ${ }^{30}$ The needs assessment is the first step in the establishment of a training and development Program.

This study illustrates that the use of permanent training need assessment system for reviewing training needs is essential to prioritize among many learning and health care needs. Training need assessment is a practical tool to enable participation in changing needs of community and organizations.

The findings of this research will be a first step in exploring new models for providing effective leadership training including training across organizations and professional categories.

\section{Limitations of the Study}

We acknowledge that this is a cross-sectional study with sample drawn from only 40 Reproductive Health and Family Planning leaders of Pakistan. Furthermore, the findings of this study are based on self-reported information and some reporting bias may have occurred.

\section{Recommendations}

All Leadership training activities should have clear objectives that describe skills that participants will be able to perform and knowledge they will be able to use as a result of participation. This is a critical step in selecting appropriate participants and in evaluating the effectiveness of the training.

The reproductive health and the family planning areas to 
improve maternal and child health should have a systematic and regular method of assessing training needs and skills development of staff.

Competency-based or skills-based training for public health professionals should use adult learning methods. Focusing on competence and skill provides accountability and is helpful in considering issues of improving performance at the organizational and individual levels.

All leadership Programs should perform a need assessment within their training designs for an effective training curriculum.

Pakistan needs to work on the development of a transparent system to combat the problems regarding inefficiency of the present structure. This entails overseeing and managing the performance and the effectiveness of the national health programs, including maternal and child health program. In the current scenario of Pakistan, Leadership training programs should focus on areas of disaster management, budget preparation and monitoring, emergency preparedness, health education and communication strategies.

\section{Acknowledgements}

We acknowledge the contribution of all study participants who provided their feedback on the survey. We would also like to thank Kamyla Marvi, Country Manager Leadership Development for mobilizing reproductive health, Pakistan chapter for her support to conduct this study.

\section{References}

[1] Janice A. Miller, SPHR and Diana M. Osinski, SPHR. "Training Needs Assessment", February 1996 Reviewed July 2002

[2] Institute of Medicine. Who will keep the public healthy? Educating public health professionals in the 21 st century. Washington: National Academies Press; 2003. Also available from: URL: http:// www.nap.edu/books/030908542X/html/

[3] Education for Health, Vol. 17, No. 3, November 2004, $346-$ 353

[4] Public Health Functions Steering Committee. Essential public health services - Adopted 1994

[5] Tyssen R, Valglum P, Gronuold T, Nina T. The relative importance of individual and organizational factors for the prevention of job stress during internship: a nationwide and prospective study. Med Teach 2005; 27(8):726-31.

[6] Myers P: The objective assessment of general practitioners' educational needs: an under-researched area? Acad Med 1991, 66(12):762-769.

[7] Department of Health and Human Services (US). The public health workforce: an agenda for the 21 st century. Washington: Department of Health and Human Services; 1997.

[8] Institute of International Education Projects. 2000. Reviewed July 2012
[9] Leadership Development for Mobilizing Reproductive Health (LDM). 2015 retrieved from http://www.iie.org/Programs/LDM

[10] Ajmal A, Amber S. Leadership Development for.Mobilizing Reproductive Health. (LDM) Pakistan Program. Evaluation Report. 2011 retrieved from www.iieldm.org/.../Pakistan\%20Evaluation\%20Full\%20Repor $\mathrm{t}$

[11] Perol D, Boissel JP, Broussole C, Cetr JC, Stagnara J, Chauvin F: A simple tool to evoke physician's real training needs. Acad Med 2002 , 77(5):407-410. Pub Med Abstract |

[12] Gordon MJ: A review of the validity and accuracy of self-assessments in health professions training. Br J Gen Pract 1999, 49(441):303-307. Pub Med Abstract | Publisher Full Text | PubMed Central Full Text

[13] Janice A. Miller, SPHR and Diana M. Osinski, SPHR. "Training Needs Assessment", February 1996 Reviewed July 2002

[14] Zemke, Ron and Thomas Kramlinger. Figuring Things Out: A Trainer's Guide to Needs and Task Analysis. Reading, MA: Addison-Wesley Publishing Company, 1982.

[15] Chaudhury N, Hammer J, Kremer M, Muralidhran K, Rogers FH: Missing in Action: teacher and health worker absence in developing countries. J Econ Perspect 2006, 20(1):91-116. PubMed Abstract | Publisher Full Text

[16] Nadler,D. 1993. Concepts for the management and organizational change. P92 in managing change, ed C Mabey and B Mayor White. London: Paul Chapman/Open Univ.

[17] Zaeem Haq AH: Knowledge and communication needs assessment of community health workers in a developing country: a qualitative study. Human resources for health 2009, $7: 59$

[18] Council on Linkages Between Academia and Practice. Core competencies for public health professionals: a practical tool to strengthen the public health workforce. The Link 2001; 15(2): 13. Also available from: URL: http://www.trainingfinder.org /competencies/list.htm 7. Department of Labor, Bureau of Labor Statistics (US). Standard

[19] Asmat Ullah M, Devolution in Pakistan: implications for district health system. School of Population Health, University of Queensland.2012

[20] Barton JR: Academic training schemes reviewed: implications for the future development of our researchers and educators. Medical education 2008, 42(2):164-169. 